\title{
Validity of an Inexpensive Hanging Scale During Isometric Shoulder Movements
}

\author{
Matheus Lima Oliveira, Isabela Christina Ferreira, Kariny Realino Ferreira, Gabriela Silveira-Nunes, \\ Michelle Almeida Barbosa, and Alexandre Carvalho Barbosa
}

\begin{abstract}
Context: Strength assessment is essential to prescribe exercise in sports and rehabilitation. Low-cost valid equipment may allow continuous monitoring of training. Objective: To examine the validity of a very low-cost hanging scale by comparing differences in the measures of peak force to a laboratory grade load cell during shoulder abduction, flexion, extension, and internal and external rotations. Design: Analytical study. Participants: Thirty-two healthy subjects (18 women, age 26 [10] y, height 172 [8] cm, mass 69 [13] kg, body mass index 23 [4] kg/m²). Main Outcome Measures: The dependent variable was the maximal peak force (in kilogram-force). The independent variable was the instrument (laboratory grade load cell and hanging scale). Results: No differences were observed while comparing the results. The intraclass correlation coefficients ${ }_{1,1}$ ranged from .96 to .99 , showing excellent results. The Cronbach alpha test also returned $>.99$ for all comparisons. The SEM ranged from 0.02 to $0.04 \mathrm{kgf}$, with an averaged SD from 0.24 to $0.38 \mathrm{kgf}$. The correlation was classified as high for all tested movements $(r>.99$; $P<.001)$, with excellent adjusted coefficients of determination $\left(.96<r^{2}<.99\right)$. Bland-Altman results showed high levels of agreement with bias ranging from 0.27 to 0.48 . Conclusions: Hanging scale provides valid measures of isometric strength with similar output measures as laboratory grade load cell.
\end{abstract}

Keywords: muscle strength, upper-extremity, isometric contraction

Shoulder weakness and muscle imbalances are both associated with shoulder pain in athletes performing overhead sports. ${ }^{1}$ Preseason shoulder external-rotation weakness is associated with supraspinatus strength deficits and in-season throwing-related injuries. ${ }^{2}$ Differences in strength between the agonist and antagonist muscle groups in the shoulder and decreased eccentric muscle strength of the external rotators are associated with the rate of injury on the shoulder girdle. ${ }^{2}$ Studies showed that muscle weakness leads to increased direct costs, placing a burden on health care system. ${ }^{3,4}$

Objective measures of muscle function provide valid information to implement effective treatment and exercise training. ${ }^{5}$ Equipments are available for measuring muscle strength, such as hand-held dynamometers and load cells. The isokinetic dynamometer (IKD) is often referred as the gold standard to which all other measures are compared. ${ }^{5}$ However, the IKD is very expensive, not portable, requires extensive staff training, and it is often restricted to laboratory environment. The laboratory grade load cell (LLC) is the optimal alternative to IKD, showing excellent results for both validity and reliability. 5,6 The LLC is often used for research purposes and requires an analog-to-digital converter, with a dedicated software to interpret the results. Despite its portability and validity, the LLC can also be expensive, and the software is usually not user friendly, requiring training and experience to avoid any assessment biases.

The hanging scale (HS) may be a cost-effective alternative to ensure accurate and safe performance for muscle strength assessments. The battery operated equipment is used for weighting in a suspended manner, with good precision and wide weight ranges. It is very portable, with an easy-to-read display. The HS uses a

The authors are with the Musculoskeletal Research Group-NIME, Department of Physical Therapy, Federal University of Juiz de Fora, Governador Valadares, MG, Brazil. Barbosa (alexwbarbosa@hotmail.com) is corresponding author. transducer principle (with a load cell), which is essentially a metallic sturdy element, yet elastic enough for a load to deform it. The transducer has an attached strain gauge, which reads the electrical resistance change when a load is placed on the transducer. The change in electrical resistance is converted to a digital signal by the strain gauge, which is readable on the display.

While LLC has demonstrated high validity, we are unaware of any studies comparing it with HS to assess shoulder muscle strength. Therefore, the purpose of this study was to examine the validity of a very low-cost HS by comparing differences in the measures of peak force to an LLC during shoulder abduction, flexion, extension, and internal and external rotations.

\section{Methods}

A convenience sample of 32 subjects (18 women, age 26 [10] y, height 172 [8] cm, mass 69 [13] kg, body mass index $23[4] \mathrm{kg} / \mathrm{m}^{2}$ ) participated in the study. Exclusion criteria included history of injury to the upper-extremity during the past 6 months, a history of neck pain, previous shoulder or neck surgery, diagnosed neurologic disorder (eg, stroke, head trauma), or current symptoms related to the neck and shoulder area. The dependent variable was the peak force (in kilogram-force). The independent variable was the instrument (LLC and HS).

Data were collected using an LLC (Miotec ${ }^{\mathrm{TM}}$; Biomedical Equipments, Porto Alegre, RS, Brazil; maximum tensioncompression $=200 \mathrm{kgf}$, precision of $0.1 \mathrm{kgf}$, maximum error of measurement $=0.33 \%$ ) attached to an acquisition module with 8 analog channels (Miotec ${ }^{\mathrm{TM}}$, Biomedical Equipments). The conversion from analog-to-digital (A/D) signals was performed by an A/D board with 16-bit resolution input range, the sampling frequency of $2 \mathrm{kHz}$, common rejection module of $>100 \mathrm{~dB}$, signal-to-noise ratio of $<03 \mu \mathrm{V}$ root mean square, and impedance of $109 \Omega$. 
The collected data were windowed at $125 \mathrm{~ms}$ and analyzed offline using the Miotec ${ }^{\mathrm{TM}}$ Suite Software. The windowing is a preprocessing technique for smoothening/filtering the signal. The size of the window is predefined in the A/D system (hardware/software) and varies between 100 and $300 \mathrm{~ms}$, according to the International Society of Electrophysiology and Kinesiology (https://isek.org). The LLC was calibrated using $10 \%$ of the maximum tensioncompression load, following the manufacturer recommendations. A new calibrated HS (model MNCS-M; Bode Technical Services, Denver, CO; maximum tension-compression $=200 \mathrm{kgf}$, precision of $0.1 \mathrm{kgf}, 5$ digits display) was used as a testing equipment.

\section{Procedures}

All testing was performed in the musculoskeletal lab at the School Clinic of Federal University of Juiz de Fora. The UFJF ethics committee for human investigation approved the procedures employed in the study. The objectives of the study were explained to the subjects, and they were notified of the benefits and potential risks involved before signing an informed consent form prior to participation. Data including height, weight, and body mass index were measured and recorded for each participant. The dominant upper limb was tested 3 times (with $5 \mathrm{~s}$ of rest; first trial was considered as familiarization) using the HS attached to the LLC, which was fixed to the wall with a chain (Figure 1). Dominant arm was defined as the arm used to write. Flexion and abduction were tested at $90^{\circ}$ of shoulder flexion and abduction, respectively. Extension was tested at $40^{\circ}$ of shoulder extension. The elbow was kept at full extension for the previous movement testing. Internal and external rotations were tested with the arm along to the body, elbow flexed at $90^{\circ}$, and neutral positioned (Figure 2). All angles were quantified through goniometric measurement.

\section{Statistical Analysis}

All trials were used for analysis, comprising a total of 64 measures. Data were presented as mean (SD). The Mann-Whitney test was used to compare differences between measures. Significance was set at $P<.05$. One-way random effects, absolute agreement, singlerater/measurement intraclass correlation coefficients $\left(\mathrm{ICC}_{1,1}\right)$ were calculated to assess the reliability between results from both equipments. The Cronbach alpha test was used to assess the

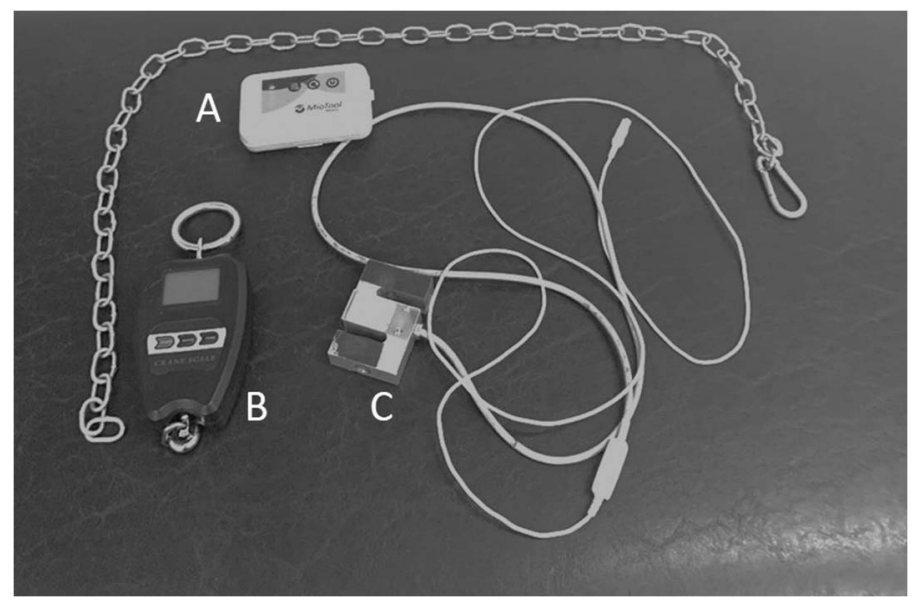

Figure 1 - Equipment's setup. (A) Analog-to-digital converter, (B) hanging scale, and (C) laboratory grade load cell. expected correlation of both equipments measuring the same construct. SEM was also calculated to provide an estimate of measurement error. Linear regression estimated the coefficient of correlation $(R)$ and the adjusted coefficient of determination $\left(R^{2}\right)$. Bland-Altman method estimated the measurement bias, with lower and upper limits of agreement between results. All statistics were done using the Jamovi software. ${ }^{8}$

\section{Results}

No differences were observed while comparing the isometric peak forces between LLC and HS $(P>.05)$. The $\mathrm{ICC}_{1,1}$ ranged from .96 to .99 , showing excellent results. The Cronbach alpha test also returned $>.99$ for all comparisons. The SEM returned a range of 0.02 to $0.04 \mathrm{kgf}$, with an averaged SD ranging from 0.24 to $0.38 \mathrm{kgf}$. The correlation was classified as high for all tested movements $(R>.99 ; P<.001)$, with excellent adjusted coefficients of determination $\left(.96<R^{2}<.99\right)$. Bland-Altman results showed high levels of agreement with bias ranging from 0.27 to 0.48 . All results are described in detail in Table 1.

\section{Discussion}

The results of this study demonstrated that the peak force recorded for shoulder movements were similar (almost the same) between the LLC and HS. These findings support the primary hypothesis, which contended that isometric peak force for the HS would reach acceptable levels of validity. To our knowledge, this is the first study in which validity has been established for HS. A previous study showed no significant differences in peak torque values between an LLC system and IKD for knee flexion and extension, proposing the LLC as the practical standard device to assess muscle strength..$^{5}$ Another study showed acceptable validity to measure the isometric peak force $(\mathrm{ICC}=.88)$ using an LLC attached to a fixed plate tested against a force platform while performing midthigh clean pull. ${ }^{9}$

Monitoring improvements on strength along training is essential for fitting the exercise to the subject's needs. The validation of the HS would help health professionals and coaches to objectively monitor strength without technical (as rater experience, previous training to use equipment/software) or financial issues (expensive equipment). The maximal isometric contraction improvements reflect combination of central and peripheral adaptations in muscle strength. ${ }^{10}$ Thus, isometric tests are available options to assess the muscle force output as they are easily standardized, requiring minimal familiarization. ${ }^{11}$ Other characteristics also reinforce the importance of maximal isometric measures. Studies showed that torque production measured at a constant angle is more sensitive to influences produced by muscle fiber type rather than angle independent peak torque during dynamic contractions. ${ }^{10,11}$

Valid and fast strength assessment could potentially reduce the risk for shoulder injuries by fitting the resistance exercise to subjects' immediate and/or future needs. Considering its portability and the very lower cost, the HS might also be considered as a valid standard equipment for shoulder muscle strength assessment. The LLC full system is around USD 2000.00, while the HS used in this study was bought for USD 37.00.

There are some limitations of this study. Intrarater and interrater reliability were not assessed. The sample included only healthy participants, and testing was conducted on the dominant 

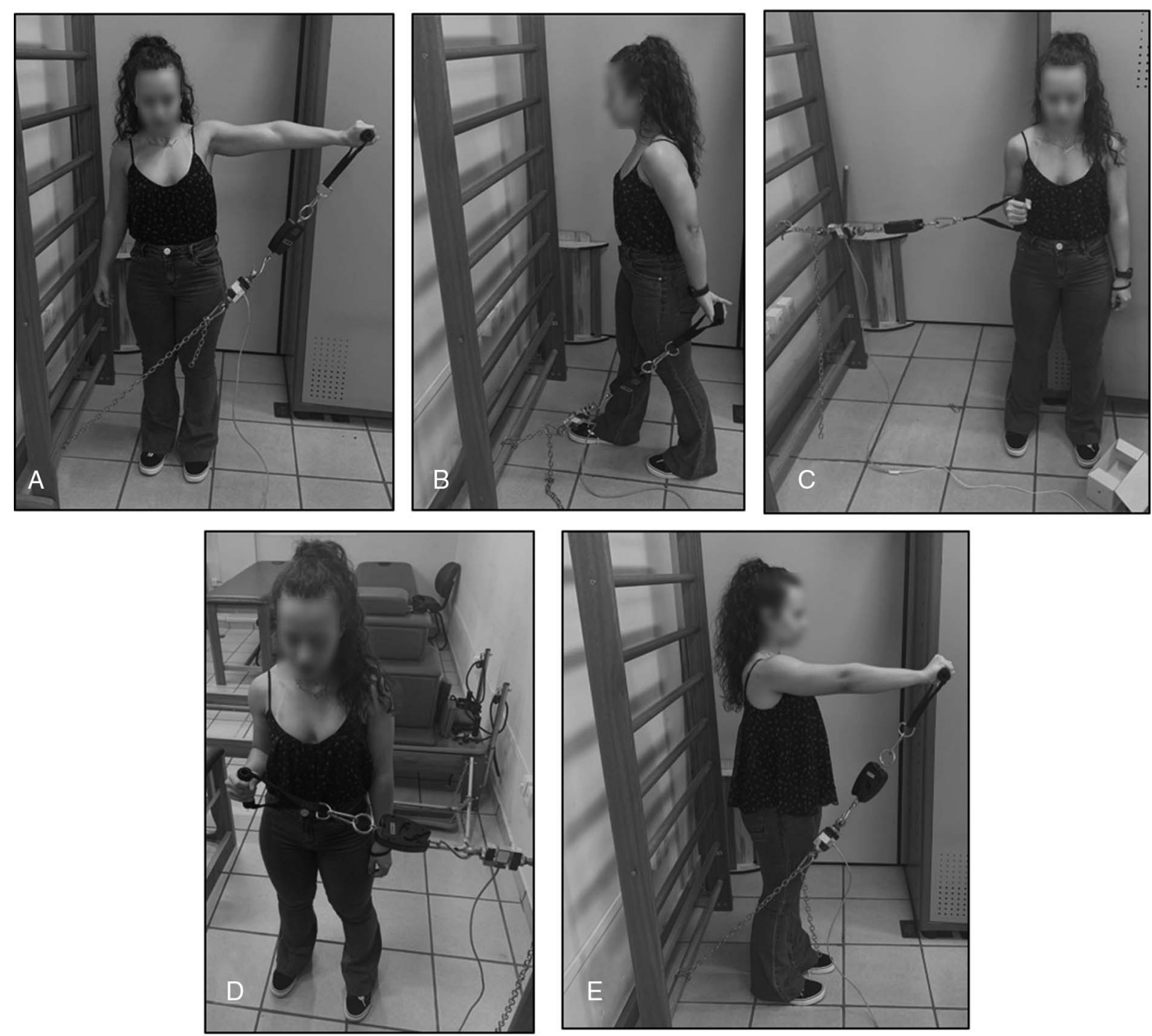

Figure 2 - Shoulder movements. (A) Abduction, (B) extension, (C) internal rotation, (D) external rotation, and (E) flexion.

Table 1 Outcome Variables With Significant Differences

\begin{tabular}{|c|c|c|c|c|c|}
\hline Outcome & Abduction & Extension & Internal rotation & External rotation & Flexion \\
\hline LLC, kgf & $7.24(2.8)$ & $8.67(4.64)$ & $9.94(4.14)$ & $7.47(2.62)$ & $7.38(2.75)$ \\
\hline $\mathrm{HS}, \mathrm{kgf}$ & $6.97(2.81)$ & $8.29(4.59)$ & $9.47(4)$ & $7.06(2.55)$ & $7.1(2.69)$ \\
\hline$P$ value (difference) & .44 & .44 & .33 & .22 & .38 \\
\hline Mean difference & 0.26 & 0.34 & 0.41 & 0.39 & 0.3 \\
\hline \multicolumn{6}{|l|}{$95 \% \mathrm{CI}$} \\
\hline Lower bound & -1.02 & -1.3 & -1.28 & -1 & -1.05 \\
\hline Upper bound & 0.52 & 0.65 & 0.43 & 0.25 & 0.44 \\
\hline $\mathrm{ICC}_{1,1}$ & .985 & .988 & .983 & .969 & .986 \\
\hline Cronbach $\alpha$ & .995 & .999 & .997 & .994 & .997 \\
\hline$R$ & .993 & .998 & .995 & .989 & .994 \\
\hline Adjusted $R^{2}$ & .986 & .996 & .989 & .978 & .988 \\
\hline$P$ value (correlation) & .001 & .001 & .001 & .001 & .001 \\
\hline
\end{tabular}


Table 1 (continued)

\begin{tabular}{lcccc}
\hline Outcome & Abduction & Extension & Internal rotation & External rotation \\
\hline Bland-Altman & & & & \\
Bias & 0.268 & 0.377 & 0.461 & 0.41 \\
LLA & -0.412 & -0.192 & -0.408 & -0.34 \\
ULA & 0.948 & 0.945 & 1.331 & 0.276 \\
SEM & 0.03 & 0.03 & 0.04 & -0.32 \\
\hline
\end{tabular}

Abbreviations: CI, confidence interval; HS, hanging scale; ICC $_{1,1}$, intraclass correlation coefficient; LLA, lower level of agreement; LLC, laboratory grade load cell; $R$, correlation coefficient; $R^{2}$, determination coefficient; ULA, upper level of agreement. Note: Descriptive data are presented in mean (SD).

limb. It is unknown whether similar results could be found in a pathological population or whether the opposite side differences exist.

The HS appears to be a valid method of assessing isometric shoulder strength. The portability, cost effectiveness, and userfriendly system provide an effective means of measuring shoulder isometric strength.

\section{Acknowledgments}

The authors would like to thank Department of Physical Therapy, University of Juiz de Fora, Governador Valadares and Diretoria de Relações Internacionais, University of Juiz de Fora. This study was financed in part by the Coordenação de Aperfeiçoamento de Pessoal de Nível Superior, Brazil (CAPES) - Finance Code 001, and by the Fundação de Amparo à Pesquisa de Minas Gerais (FAPEMIG).

\section{References}

1. McLaine SJ, Ginn KA, Fell JW, Bird ML. Isometric shoulder strength in young swimmers. J Sci Med Sport. 2018;21(1):35-39. PubMed ID: 28844605 doi:10.1016/j.jsams.2017.05.003

2. Johansson FR, Skillgate E, Lapauw ML, et al. Measuring eccentric strength of the shoulder external rotators using a handheld dynamometer: reliability and validity. J Athl Train. 2015;50(7):719-725. PubMed ID: 25974381 doi:10.4085/1062-6050-49.3.72

3. Pinedo-Villanueva R, Westbury LD, Syddall HE, et al. Health care costs associated with muscle weakness: a UK population-based estimate. Calcif Tissue Int. 2019;104(2):137-144. PubMed ID: 30244338 doi: 10.1007/s00223-018-0478-1
4. Steffl M, Sima J, Shiells K, Holmerova I. The increase in health care costs associated with muscle weakness in older people without longterm illnesses in the Czech Republic: results from the Survey of Health, Ageing and Retirement in Europe (SHARE). Clin Interv Aging. 2017;12:2003-2007. PubMed ID: 29225462 doi:10.2147/ CIA.S150826

5. Toonstra J, Mattacola CG. Test-retest reliability and validity of isometric knee-flexion and -extension measurement using 3 methods of assessing muscle strength. J Sport Rehabil. 2013;22(1). doi:10. 1123/jsr.2013.TR7

6. Buckner SL, Jenkins NDM, Costa PB, Ryan ED, Herda TJ, Cramer JT. Comparing passive angle-torque curves recorded simultaneously with a load cell versus an isokinetic dynamometer during dorsiflexion stretch tolerance assessments. Med Eng Phys. 2015;37(5):494-498. PubMed ID: 25782330 doi:10.1016/j.medengphy.2015.02.010

7. Hanafee JE, Radcliffe SV. Effect of high pressure on a strain gauge load cell. Rev Sci Instrum. 1967;38(3):328-331. doi:10.1063/1.1720698

8. Jamovi [computer software]. Version 0.9. The Jamovi Project; 2019. https://www.jamovi.org

9. James LP, Roberts LA, Haff GG, Kelly VG, Beckman EM. Validity and reliability of a portable isometric mid-thigh clean pull. J Strength Cond Res. 2017;31(5):1378-1386. PubMed ID: 28415068 doi:10. 1519/JSC.0000000000001201

10. Peltonen H, Walker S, Lähitie A, Häkkinen K, Avela J. Isometric parameters in the monitoring of maximal strength, power, and hypertrophic resistance-training. Appl Physiol Nutr Metab. 2018; 43(2):145-153. PubMed ID: 29017022 doi:10.1139/apnm-2017-0310

11. Peltonen H. Isometric force-time parameters in monitoring of strength training: with special reference to acute responses to different loading resistances. Stud Sport Phys Educ Health. 2017;264:96-97. https:// jyx.jyu.fi/handle/123456789/56014. Accessed May 21, 2019. 